\title{
Cellular Systems and Biomaterials for Nerve Regeneration in Neurotmesis Injuries
}

\author{
Ana Colette Maurício ${ }^{1,2}$ et al.*, \\ ${ }^{1}$ Centro de Estudos de Ciência Animal (CECA), Instituto de Ciências e Tecnologias \\ Agrárias e Agro-Alimentares (ICETA), Universidade do Porto (UP), \\ 2Instituto de Ciências Biomédicas Abel Salazar (ICBAS), UP, \\ Portugal
}

\section{Introduction}

A relevant number of peripheral nerve injuries can only be dealt through reconstructive surgical procedures. Despite continuous refinement of microsurgery techniques, peripheral nerve repair still stands as one of the most challenging tasks in neurosurgery. Particularly problematic is the fact that despite the good regenerative ability of peripheral nerves and successful surgical nerve repair functional recovery is most often disappointing in these patients (Lundborg, 2002). While direct nerve repair should be the procedure of choice whenever tension-free suturing is possible, in many cases there is a significant loss of nerve tissue and resulting nerve gap. In these cases a nerve graft might be necessary for adequate nerve repair (Lundborg, 2002). Nerve grafting, however have some disadvantages, the most prominent being donor site morbidity that may lead to a secondary sensory deficit and occasionally neuroma and pain. In addition, non-matching donor and recipient nerve diameters often occur, which might be at the basis of poor functional recovery (May, 1983). Entubulation offers advantages over autographs, including the potential to manipulate the regeneration environment within the tube-guide (Fields et al., 1989). Consequently, guidance of regenerating axons is not only achieved by a mechanical effect but also by a chemical effect (such as accumulation of neurotrophic factors) (Meek \& Coert, 2002). Nerve guides can be made of biological or synthetic materials and, among the latter, both nonabsorbable (e.g. silicon) and biodegradable tubes have been used (Schmidt \& Leach, 2003). Biodegradable nerve guides must be preferred since no foreign body material will be left in

\footnotetext{
*Andrea Gärtner 1,2, Paulo Armada-da-Silva ${ }^{3}$, Sandra Amado3, Tiago Pereira ${ }^{1,2}$, António Prieto Veloso3, Artur Varejão ${ }^{4}$, Ana Lúcia Luís ${ }^{1,2}$ and Stefano Geuna ${ }^{5}$

${ }^{1}$ Centro de Estudos de Ciência Animal (CECA), Instituto de Ciências e Tecnologias Agrárias e Agro-Alimentares (ICETA), Universidade do Porto (UP), Portugal.

${ }^{2}$ Instituto de Ciências Biomédicas Abel Salazar (ICBAS), UP, Portugal.

${ }^{3}$ Faculdade de Motricidade Humana (FMH), Universidade Técnica de Lisboa (UTL), Portugal.

${ }^{4}$ Departamento de Ciências Veterinárias, CIDESD, Universidade de Trás-os-Montes e Alto Douro (UTAD),

Portugal

${ }^{5}$ Neuroscience Institute of the Cavalieri Ottolenghi Foundation \& Department of Clinical and Biological Sciences, University of Turin, Italy
} 
the host after the device has fulfilled its task. Four types of nerve guides attracted particular attention of our research group: those made of PLGA (Luis et al., 2007b; Luis et al., 2008) and poly-ع-caprolactone (Luis et al., 2008; Varejao et al., 2003a), collagen (Amado et al., 2010) and chitosan (Amado et al., 2008). In particular, chitosan has recently attracted particular attention because of its biocompatibility, biodegradability, low toxicity, low cost, enhancement of wound-healing and antibacterial effects and its potential usefulness in nerve regeneration have been demonstrated both in vitro and in vivo (Amado et al., 2010; Shirosaki et al., 2005; Simoes et al., 2010). Chitosan is a partially deacetylated polymer of acetyl glucosamine obtained after the alkaline deacetylation of chitin (Senel \& McClure, 2004). While chitosan matrices have low mechanical strength under physiological conditions and are unable to maintain a predefined shape after transplantation, their mechanical properties can be improved by modification with a silane agent, namely $\gamma^{-}$ glycidoxypropyltrimethoxysilane (GPTMS), one of the silane-coupling agents which has epoxy and methoxysilane groups. The epoxy group reacts with the amino groups of chitosan molecules, while the methoxysilane groups are hydrolyzed and form silanol groups, and the silanol groups are subjected to the construction of a siloxane network due to the condensation. Thus, the mechanical strength of chitosan can be improved by the crosslinking between chitosan, GPTMS and siloxane network. We have previously obtained by adding GPTMS, chitosan type III membranes (hybrid chitosan membranes) which have about $110 \mu \mathrm{m}$ pores and about $90 \%$ of porosity, due to the employment of freeze-drying technique, and which were successful in improving sciatic nerve regeneration after axonotmesis (Amado et al., 2008). Wettability of the material surfaces is one of the key factors for protein adsorption, cell attachment and migration (Amado et al., 2008). The addition of GPTMS improves the wettability of chitosan surfaces, and therefore chitosan type III membranes are more hydrophilic than types of chitosan membranes (Shirosaki et al., 2005). In addition, chitosan type III was developed to be more porous, with a larger surface to volume ratio, and to preserve mechanical strength and ability to adapt to different shapes. Significant differences in water uptake between commonly used chitosan and our hybrid chitosan type III were previously reported and it has been shown that they retain about two times as much biological fluid (Tateishi et al., 2002). The Neurolac ${ }^{\circledR}$ and the PLGA90:10 tube-guides guides show several different physical-chemical properties, namely Neurolac ${ }^{\circledR}$ is stiffer than PLGA due to structural reinforcement of the ester bonds and does not degrade so quickly. The biodegradation rate of PLGA tubes is estimated to be around 3 months while that complete resorption of Neurolac ${ }^{\circledR}$ is estimated to be of 16 months approximately (Geuna et al., 2009; Luis et al., 2007b; Luis et al., 2008). The degradation products of Neurolac ${ }^{\circledR}$ are less acidic, which may cause less damage to the surrounding tissue, and they are transparent so that the correct positioning of the nerve stumps may be confirmed after suturing. On the other hand, the biodegradable non woven structure of PLGA tubes may offer some advantages in terms of microporosity which may enhance nerve repair (Luis et al., 2007b; Luis et al., 2008). In vitro studies have shown that the four types of tube-guides, namely, the PLGA, the collagen, the hybrid chitosan and the Neurolac ${ }^{\circledR}$ are biocompatible to nerve cells and can facilitate nerve cell attachment, differentiation and growth (Amado et al., 2008; Luis et al., 2007b; Luis et al., 2008; Luis et al., 2008; Wang et al., 2008). Our research group tested the PLGA90:10, the hybrid chitosan type III and the collagen tube-guides covered with the neural cells in vitro differentiated for 48 hours in the presence of DMSO (Amado et al., 2010; Amado et al., 2008; Luis et al., 2008; Simoes et al., 2010). The Neurolac ${ }^{\circledR}$ tubes were not tested with the cellular system, since the 
cell adherence was more difficult to obtain and imply the previous covering with poli-1lysine (Amado et al., 2010; Amado et al., 2008; Luis et al., 2008; Simoes et al., 2010). It is expected that tissue engineering associating these biomaterials to cellular systems, capable of differentiating into neuron-like cells, may improve peripheral nerve regeneration, in terms of motor, sensory and histomorphometric parameters. The N1E-115 cells derived from mouse neuroblastomas (Amano et al., 1972) can in vitro differentiate into neural-cells (Amano et al., 1972; Rodrigues et al., 2005) and were used as a cellular model for stem cells. In addition, mesenchymal cells isolated from the Wharton's jelly of the umbilical cord, were used by our research group (data not published yet). Stem cells can be loosely classified into 3 broad categories based on their time of isolation during ontogenesis: embryonic, fetal and adult (Marcus \& Woodbury, 2008). Recent years have witnessed an explosion in the number of adult stem cells populations isolated and characterized. While still multipotent, adult stem cells have long been considered restricted, giving rise only to progeny of their resident tissues. Recently, and currently controversial studies have challenged this dogma, suggesting that adult stem cells may be far more plastic than previously appreciated (Marcus \& Woodbury, 2008). Extra-embryonic tissues as stem cell reservoirs offer many advantages over both embryonic and adult stem cell sources. Extra-embryonic tissues, collectively known as the afterbirth, are routinely discarded at parturition, so little ethical controversy attends the harvest of the resident stem cell populations. Most significantly, the comparatively large volume of extra-embryonic tissues and ease of physical manipulation theoretically increases the number of stem cells that can be isolated (Marcus \& Woodbury, 2008). The umbilical cord contains two arteries and one vein protected by a proteoglycan rich connective tissue called Wharton's jelly. Within the abundant extracellular matrix of Wharton's jelly resides a recently described stem cell population called Umbilical Cord Matrix Stem Cells. It can be isolated around 400,000 cells per umbilical cord, which is significantly greater than the number of MSCs that can be routinely isolated from adult bone marrow. In vitro the Wharton's jelly MSCs cells are capable of differentiation to multiple mesoderm cell types including skeletal muscle and neurons (Fu et al., 2006; Wang et al., 2004). Human MSCs (HMSCs) isolated from Wharton's jelly of the umbilical cord can be easily and ethically obtained and processed compared with embryonic or bone marrow stem cells. These cells may be a valuable source in the repair of the peripheral nerve system. HMSCs from Wharton's jelly of the umbilical cord possess stem cell properties (Yang et al., 2008) and it was previously demonstrated that HMSCs could be induced to differentiate into neuron-like cells (Fu et al., 2006). The transplanted cells were able to promote local blood vessel formation and expression of the neurotrophic factors, brain-derived neurotrophic factor (BDNF) and glial cell line-derived neurotrophic factor (GDNF) (Wang et al., 2004). Therefore, the purpose to cover the PLGA 90:10, hybrid chitosan, and collagen tube-guides used in reconstructed nerves after neurotmesis with a cellular system differentiated in vitro into neuronal cells, was to produce locally neurotrophic factors in a physiological concentration. The role of neurotrophic factors in neural regeneration has been the focus of extensive research (Amado et al., 2010; Hu et al., 1997). The influence of these factors in neural development, survival, outgrowth, and branching has been explored on various levels, from the molecular level to the macroscopic tissue responses. Neurotrophic factors promote a variety of neural responses, like the survival and outgrowth of the motor and sensory nerve fibers, and are implicated in spinal cord and peripheral nerve regeneration (Geuna et al., 2009; Johnson et al., 2008). However, in vivo, the efficacy of neurotrophic factors might vary greatly due to the method used for their delivering and it is thus 
important to deliver them near the regenerating site, in the physiologic concentrations. In this view, association of a cellular system producing neurotrophic factors to biodegradable membranes may greatly improve the nerve regeneration in neurotmesis (Geuna et al., 2009). N1E-115 cell line established from a mouse neuroblastoma (Kerns et al., 1991), might be a useful cellular system to locally produce and deliver these neurotrophic factors (Geuna et al., 2001). In vitro, the N1E-115 cells undergo neuronal differentiation in response to dimethylsulfoxide (DMSO), adenosine 3', 5'- cyclic monophosphate (cAMP), or serum withdrawal (Koka \& Hadlock, 2001; Luis et al., 2007b; Luis et al., 2008; Luis et al., 2008). Upon induction of differentiation, proliferation of N1E-115 cells ceases, extensive neurite outgrowth is observed and the membranes become highly excitable (Koka \& Hadlock, 2001; Luis et al., 2007b; Luis et al., 2008). The ideal interval period of 48 hours of differentiation was determined by measurement of the intracellular calcium concentration $\left(\left[\mathrm{Ca}^{2+}\right]_{\mathrm{i}}\right)$, when the N1E-115 cells presented already the morphological characteristics of neuronal cells but at a time, cell death due to increased $\left[\mathrm{Ca}^{2+}\right]_{\mathrm{i}}$ was not still occurring (Rodrigues et al., 2005).

\section{Biomaterial for tube-guides fabrication}

The tube-guides or scaffold of tissue engineered nerve grafts serve in neurotmesis injuries to direct axons sprouting from the proximal to the distal stump, to maintain adequate mechanical support for the regenerating nerve fibers. Yet, they provide a conduit channel for the diffusion of neurotrophic and neurotropic factors secreted in the regeneration local and provide a conduit wall for the exchange of nutrients and waste products with the surrounding media, limiting the infiltration of fibrous scar tissue that hinders axonal regeneration (Johnson \& Soucacos, 2008;). The neural scaffolds should be easy to be fashioned in different lengths and diameters, to be sterilized and implanted using microsurgical techniques. The neural scaffold has to satisfy many biological and physicochemical requirements like biocompatibility, biodegradability, permeability to ions, metabolites and for the revascularization of the regenerated nerve, biomechanical properties and surface properties that modulate the cellular system adhesion (Huang \& Huang, 2006). A wide variety of biomaterials has been attempted which are of either natural or synthetic origin.

\subsection{Natural biomaterials}

The natural biomaterials are known by stimulating cell adhesion, migration, growth and proliferation. The natural biomaterials have also a very good biocompatibility and less toxic effects. Our research group has tested the collagen and the chitosan.

Collagen, laminin and fibronectin play an important role in the development and growth of axons (Grimpe \& Silver, 2002). So, these components have become very important candidates for neural scaffolds, these materials can also serve as delivery vehicles for support cells, growth factors and drugs. For example, silicone tubes filled with laminin, fibronectin, and collagen led to a better regeneration over a $10 \mathrm{~mm}$ rat sciatic nerve gap compared to empty silicone controls (Chen et al., 2007). Collagen filaments have also been used to guide regenerating axons across 20-30 mm defects in rats (Itoh et al., 2003; Yoshii \& Oka, 2001). Further studies have shown that oriented fibers of collagen within gels, aligned using magnetic fields, provide an improved template for neurite extension compared to randomly oriented collagen fibers (Ceballos et al., 1999). Finally, rates of regeneration comparable to those using a nerve autograft have been achieved using collagen tubes 
containing a porous collagen-glycosaminoglycan matrix (Archibald et al., 1995; Chamberlain et al., 2000). In our studies we have used equine collagen type III membrane (GentaFleece®; Baxter, Nuremberg, Germany) in axonotmesis and neurotmesis lesion of the rat sciatic nerve with very promising results (Amado et al., 2010; Luis et al., 2008).

Chitin is the second most abundant polysaccharide found in nature next to cellulose. It is a biopolymer of N-acetyl-D-glucosamine monomeric units and it has been used in a wide range of biomedical devices. Chitosan is a copolymer of D-glucosamine and N-acetyl-Dglucosamine and it has a very similar molecular structure with lamin, fibronectin and collagen. So, the chitosan has favorable biological properties for the nerve regeneration and it is easier to process than the chitin. Chitosan is quite fragile in its dry form, so, it has to undergo chemical cross-linking or to be used with other biomaterials before scaffold fabrication. The chitosan (high molecular weight, Aldrich ${ }^{\circledR}$, USA) tested by our research group was dissolved in $0.25 \mathrm{M}$ acetic acid aqueous solution to a concentration of $2 \%(\mathrm{w} / \mathrm{v})$. To obtain type III membranes, GPTMS (Aldrich ${ }^{\circledR}$, USA) was also added to the chitosan solution and stirred at room temperature for $1 \mathrm{~h}$. The drying process for type III chitosan membrane was as follows: the solutions were frozen for $24 \mathrm{~h}$ at $-20^{\circ} \mathrm{C}$ and then transferred to the freeze-dryer, where they were left $12 \mathrm{~h}$ to complete dryness. The chitosan type III membranes were soaked in $0.25 \mathrm{~N}$ sodium hydroxide aqueous solution to neutralize remaining acetic acid, washed well with distilled water, and freeze dried (Amado et al., 2008). All membranes used in vivo testing, were sterilized with ethylene oxide gas, considered by some authors the most suitable method of sterilization for chitosan membranes (Marreco et al., 2004). Prior to their use in vivo, membranes were kept 1 week at room temperature to clear any ethylene oxide gas remnants (Amado et al., 2008; Simoes et al., 2010) (see Fig.1).

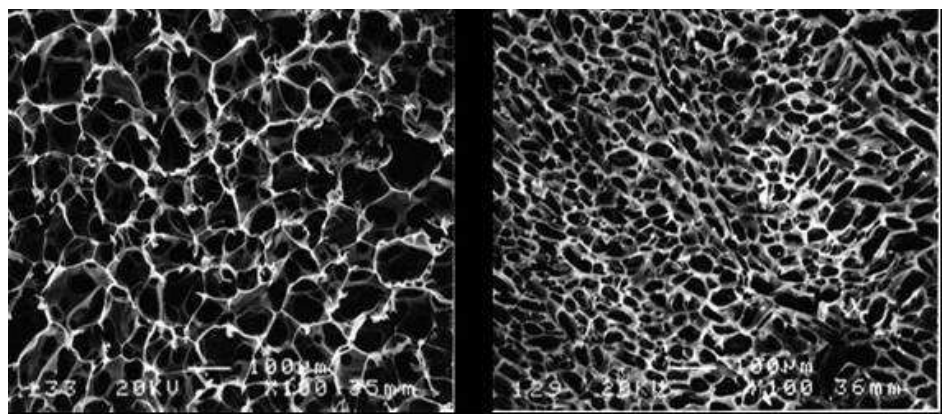

Fig. 1. SEM microstructure of chitosan membranes. Type II chitosan membrane (A). Type III chitosan membrane, showing a more porous microstructure, when compared to type II chitosan membrane (B) (Amado et al., 2008).

\subsection{Synthetic biomaterials}

The synthetic biopolymers constitute a group of promising biomaterials for the fabrication of neural tube-guides. However, the biocompatibility of some synthetic materials can be low since the difficulty of cell adhesion and survival can be a negative issue. Historically, non degradable synthetic materials were tested before the degradable ones. For instance, the silicone has been tested for peripheral nerve repair since 1960. Although it is not degradable in the body and it is impermeable to large molecules, the silicone tube-guide was an 
important model system for studying nerve regeneration. It was also applied in several clinical trials to bridge short nerve gaps with some success (Gu et al., 2011). The use of nondegradable tube-guides implies a second surgery time, which has clear disadvantages for the patient. In order to overcome the disadvantages associated with non-degradable materials, research has been focused in biodegradable synthetic biomaterials that should degrade within a reasonable time span. The degradation products absorbed should not be toxic or induce a foreign body reaction. Moreover, the physiochemical and biological properties of biodegradable synthetic materials can be tailored to match different application requirements, like to entrap some molecules or serve as a support for a cellular system. Aliphatic polyesters represent a class of the common degradable synthetic polymers, among which poly(L-lactic acid) (PLLA) (Wang et al., 2009), polyglycolic acid (PGA) (Waitayawinyu et al., 2007), polycaprolactone (PCL) (Mligiliche et al., 2003) and their copolymers, including poly(lactic- $\varepsilon$-caprolactone (Neurolac $\left.{ }^{\circledR}\right)$ (Den Dunnen et al., 1998; Luis et al., 2007b) and poly(L-lactic-co-glycolic acid (PLGA) (Bini et al., 2004; Luis et al., 2007b; Luis et al., 2008). Among synthetic biodegradable tubes, two types attracted particular attention: those made of PLGA and those made of Poly (DL-lactide- $\varepsilon$-caprolactone) copolyester (Neurolac®) (see Fig.2).
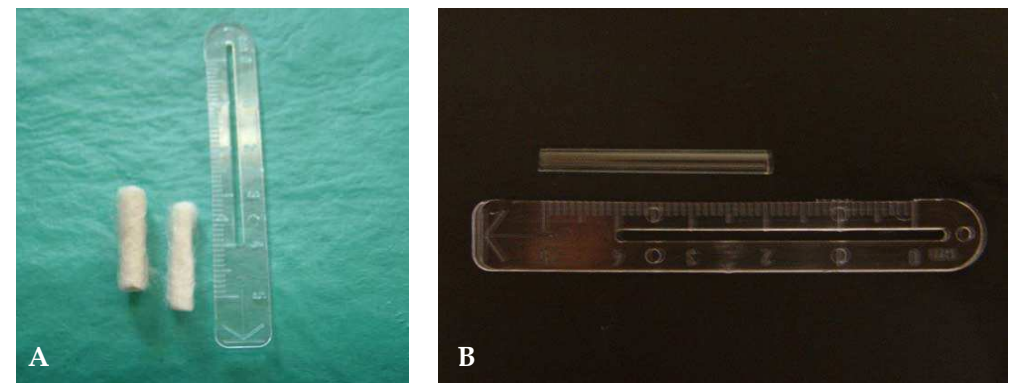

Fig. 2. PLGA 90:10 (A) and poly (DL-lactide-e-caprolactona) copolyester (Neurolac ${ }^{\circledR}$ ) tubeguides (B) (Luis et al., 2007b).

These two types of nerve guides showed several different physical-chemical properties. The Poly (DL-lactide- $\varepsilon$-caprolactone) tube-guides (Neurolac®), $16 \mathrm{~mm}$ long, internal diameter of $2 \mathrm{~mm}$ and thickness wall of $1.5 \mathrm{~mm}$, were purchased from Polyganics BV, Groningen, The Netherlands (Luis et al., 2007b; Luis et al., 2008). Poly (dl-lactide-co-glycolide) copolymers with ratio of 90PLA:10PLG were obtained from their cyclic dimers, dl-lactide and glycolide. Non-woven constructs were used to prepare tube-guides $16 \mathrm{~mm}$ long, internal diameter of $2.0 \mathrm{~mm}$ and thickness wall of $1.5 \mathrm{~mm}$, to be applied in a $10-\mathrm{mm}$ sciatic nerve gap. These fully synthetic non-woven materials are extremely flexible, biologically safe and are able to sustain the compressive forces due to body movement after implantation. They have also some degree of porosity to allow for influx of low molecular nutrients required for nerve regeneration. The non-woven structure allowed the tube-guide to hold suture without difficulties, however greater care had to be taken in order to ensure its integrity. These tubeguides of PLGA are expected to degrade to lactic and glycolic acids through hydrolysis of the ester bonds (Luis et al., 2007b; Luis et al., 2008).

The polyvinyl alcohol hydrogel (PVA) tube-guides are now starting to be tested by our research groups. Previous studies showed the PVA potential to several biomedical 
applications (Grant et al., 2006). The PVA gathers a set of exceptional properties, based in a nanofibrilar 3D structure, namely its high biocompatibility: it practically does not induce any foreign body or inflammatory reaction; it has high capacity to absorb water, mechanical resistance, elasticity, mobility and suturability (Bichara et al., 2010). The PVA are prepared in a tubular form, with $16 \mathrm{~mm}$ long, an internal diameter of $2 \mathrm{~mm}$ and thickness wall of 1.5 $\mathrm{mm}$. These forms are prepared by a casting route to a mould that allows the final shape and thickness. Among the several methods described for the preparation of PVA material, the physical cross-linking of PVA by cyclic freezing and thawing is the one with better mechanical results (data not published by our research group). PVA from Aldrich (Mowiol 10-98: Mw 61,000, 98.0-98.8 mol\% hydrolysis) is used. The tube-guides are produced using a solution of $20 \%(\mathrm{~m} / \mathrm{v})$ of PVA submitted to 3 repetitions of a freeze/thaw cycle, using 8 hours of freezing at $-20.0^{\circ} \mathrm{C}$ and 4 hours of thawing at $22^{\circ} \mathrm{C}$. However, several freeze/thaw cycling schemes must be tested to evaluate their effect on the final physical and mechanical properties, and choose the best one. The possible involvement of a final annealing step in the production process is being considered. This type of nerve guides can have unlimited availability in terms of diameters and lengths.

\section{Cellular systems}

The use of neural scaffolds alone to repair peripheral nerve defects have achieved variable success, but only small gap nerve repair (of $10 \mathrm{~mm}$ in rat sciatic nerve and of $30 \mathrm{~mm}$ in primate ulnar nerve) demonstrated evident functional and morphologic recovery (Amado et al., 2010; Gu et al., 2011; Hood et al., 2009; Luis et al., 2007b; Luis et al., 2008; Simoes et al., 2010). When the length of nerve gaps are increased, neural scaffolds alone only permit the bridging between the stumps, but for an effective regeneration, supporting cells or growth factors should be incorporated. The cellular systems implanted into the injury nerve may produce growth factors or ECM molecules, or may modulate the inflammatory process, to improve nerve regeneration (Amado et al., 2010; Gu et al., 2011; Luis et al., 2007b; Luis et al., 2008; Simoes et al., 2010). Schwann cells, mesenchymal stem cells, embryonic stem cells, marrow stromal cells are the most studied candidates of support cells among others. We focused our research in N1E-115 cell line in vitro differentiated (Amado et al., 2010; Luis et al., 2007b; Luis et al., 2008; Simoes et al., 2010) and in mesenchymal stem cells from Wharton's jelly of the umbilical cord (data not published yet).

To implant cultured cells (N1E-115 cells, MSCs, Schwann cells, and other cellular systems) into defective nerves (with axonotmesis and neurotmesis injuries), there are two main techniques. The cellular system may be directly injected to the neural scaffold which has been interposed between the proximal and distal nerve stumps or around the crush injury (in neurotmesis and axonotmesis injuries, respectively). In alternative, implant can also be achieved by pre-adding the cells to the neural scaffold via injection or co-culture (in most of the cellular systems, it is allowed to form a monolayer) and then the biomaterial with the cellular system is implanted in the injured nerve (Amado et al., 2010; Luis et al., 2008; Luis et al., 2008; Simoes et al., 2010).

\subsection{Cell culture of N1E-115 cells - a cellular model for stem cells transplantation}

The role of neurotrophic factors in neural regeneration has been the focus of extensive research in nerve regeneration (Schmidt \& Leach, 2003). The influence of these factors in neural development, survival, outgrowth, and branching has been explored on various 
levels, from molecular interactions to macroscopic tissue responses. One family of neurotrophic factors, the neurotrophins, has been heavily investigated in nerve regeneration studies, including the nerve growth factor (NGF), brain-derived neurotrophic factor (BDNF), neurotrophin-3 (NT-3), and neurotrophin-4/5 (NT-4/5) (Lundborg et al., 1994). Neurotrophic factors promote a variety of neural responses: survival and outgrowth of the motor and sensory nerve fibers, spinal cord and peripheral nerve regeneration (Schmidt \& Leach, 2003). However, in vivo responses to neurotrophic factors can vary due to the method of their delivering. Therefore, the development and use of highly controlled delivery devices are required for the study of these extremely complex systems. For that reason, N1E-115 cell line established from neuroblastoma, that undergo neuronal differentiation in response to dimethylsul-foxide (DMSO), adenosine 3'; $5^{\prime}$-cyclic monophosphate (cAMP), or serum withdrawal (Amado et al., 2010; Rodrigues et al., 2005) was a cellular system tested in axonotmesis and neurotmesis lesions to locally produce and deliver these neurotrophic factors. Upon induction of differentiation, proliferation of N1E-115 cells ceases, extensive neurite outgrowth is observed and the membranes become highly excitable (Amado et al., 2010; Rodrigues et al., 2005). During differentiation, cyclin-dependent kinase (cdk) activities decline and phosphorylation of the retinoblastoma gene product $(\mathrm{pRb})$ is lost, leading to the appearance of a pRb-containing E2F DNA-binding complex. The molecular mechanism by which $\mathrm{pRb}$ inhibits cell proliferation is becoming increasingly clear. $\mathrm{pRb}$ inhibits the activity of proteins that function as inducers of DNA synthesis (Kranenburg et al., 1995). $\mathrm{Ca}^{2+}$ serves as an important intracellular signal for cellular processes such as growth and differentiation. Free calcium levels within neural cells control many essential neural functions including neurotransmitter release, membrane conductance, nerve fibber excitability, coupling between neuronal cells, and axonal transport. Although regulation of the intracellular $\mathrm{Ca}^{2+}$ concentration $\left(\left[\mathrm{Ca}^{2+}\right]_{i}\right)$ is important for normal cell functioning, its deregulation has been linked to cellular pathologies and cell death (Trump \& Berezesky, 1995). Deregulation in $\left[\mathrm{Ca}^{2+}\right]_{i}$ can be toxic to cells and is involved in the triggering of events leading to excitotoxic cell death in neurons, through the activation of calpain, phospholipases and endonucleases (Smith \& Hall, 1988). Because of the importance of $\left[\mathrm{Ca}^{2+}\right]_{i}$ in neuronal health and disease, a relatively simple cell model system, where $\left[\mathrm{Ca}^{2+}\right]_{i}$ regulation can be studied fairly easily, is desirable. We have tested a non-expensive and easy method to culture neural-like cell line capable of producing locally, nerve growth factors and of growing inside PLGA90:10, chitosan and collagen tubular/membrane nerve guides (Amado et al., 2010; Amado et al., 2008; Luis et al., 2008; Luis et al., 2008; Simoes et al., 2010), in order to use them to promote nerve regeneration across a peripheral nerve gap. To correlate the neuronal cells' ability to promote nerve regeneration across a gap, through their differentiation grade and survival capacity, the $\left[\mathrm{Ca}^{2+}\right]_{i}$ of non-differentiated and DMSO differentiated N1E-115 cells was determined by the epifluorescence technique using the Fura-2-AM probe (Tsien, 1989). The measurement of $\left[\mathrm{Ca}^{2+}\right]_{i}$ permitted to determine an ideal period of differentiation of 48 hours, when the N1E-115 cells presented already the morphological characteristics of neuronal cells and at the same time, the death process was not initiated by the $\left[\mathrm{Ca}^{2+}\right]_{\mathrm{i}}$ modifications. This cellular system was used in axonotmesis and neurotmesis injuries associated to chitosan, equine collagen type III and PLGA membranes or tube-guides in order to improve the functional and morphologic recovery of the nerve (Amado et al., 2010; Gu et al., 2011; Luis et al., 2007b; Luis et al., 2008; Simoes et al., 2010). 


\subsection{Wharton's jelly mesenchymal cells}

After peripheral nerve injury, many neurons die. Because neurons cannot be easily expanded in vitro, there is a wide difficulty in applying primary cultured neurons to nerve tissue engineering. Embryonic stem cells (ESCs) have a great potential to proliferate unlimitedly and differentiate into neural cells using several differentiation protocols (Gu et al., 2011). The differentiation of ESCs can be modulated by growth factors and retinoic acid (Gu et al., 2011). Extensive research has been focused on the implantation of these stem cells in Central Nervous System (CNS) disorders, but in Peripheral Nerve System (PNS) injuries only a few studies were published. Cui and co-workers, in 2008, implanted ESC-derived neural progenitor cells into a 10-nm sciatic nerve gap, resulting in substantial axonal regrowth and nerve repair (Cui et al., 2008). The implanted cells survived for 3 months and could differentiate into myelinating cells. The nerve stumps presented almost normal diameter with longitudinally oriented, densely packed Schwann cell-like arrangement. The regenerated nerves also showed recovery of the functional activity, determined by electrophysiological records (Cui et al., 2008). Although these promising results, the ESCs have serious ethical issues, especially when obtained by somatic nuclear transfer technique or from embryos produced for assisted medical reproduction.

Recent years have witnessed a great expansion in the number of adult stem cell populations isolated and characterized. Adult stem cells have long been considered restricted, considering their multipotency. Many studies have challenged this dogma, suggesting that adult stem cells may be more plastic than previously appreciated (Beer et al., 2001). Extraembryonic tissues as stem cell reservoirs offer many advantages over embryonic and adult stem cell sources, and are routinely discarded at parturition. Little ethical controversy attends the harvest of the resident stem cell populations. Human umbilical cord (UC) consists of three tissue components including the (1) amniotic membrane, (2) stroma (namely, Wharton's jelly), and (3) blood vessels (two arteries and one vein). The stroma is also further divided into three histological zones including the (1) subamniotic zone, (2) intervascular zone, and (3) perivascular zone (Can \& Karahuseyinoglu, 2007). Wharton's jelly (WJ) is a proteoglycan rich connective tissue of the UC. Within the abundant extracellular matrix of WJ resides a recently described stem cell population called UC Matrix Stem Cells. Can be isolated around 400,000 cells per UC, which is significantly greater than the number of MSCs that can be routinely isolated from adult bone marrow. Isolated MSCs express CD29 and CD54, consistent with a mesenchymal cell type, and can be propagated in culture for more than 80 population doublings (Marcus \& Woodbury, 2008). In vitro the WJ MSCs cells are capable of differentiation to multiple mesodermal cell types. This cells have been successfully differentiated into various cell types including adipocytes (Karahuseyinoglu et al., 2008), chondrocytes (Baksh et al., 2007; Wang et al., 2004), osteocytes (Baksh et al., 2007; Conconi et al., 2006; Wang et al., 2004), cardiomyocytes (Kadivar et al., 2006; Wang et al., 2004), skeletal myocytes (Conconi et al., 2006), hepatocytes (Kadivar et al., 2006), insulin-producing cells (Wu et al., 2009) as well as neuron-like cells (Fu et al., 2006; Weiss et al., 2006) (see Fig.3).

Generation of clinically important dopaminergic neurons has been also reported by other groups (Fu et al., 2006; Wang et al., 2004). MSCs isolated from WJ may be a valuable cellular system to improve peripheral nerve regeneration, since they possess stem cell properties and are able to differentiate in vitro into neuron-like cells (Fu et al., 2006; Yang et al., 2008). The transplanted cells are able to promote local blood vessel formation and to locally 
produce neurotrophic factors like BDNF and GDNF (Wang et al., 2004). Transformed MSCs are still viable 4 months after transplantation without the need for immunological suppression, suggesting them as good source for Regenerative Medicine (Fu et al., 2006).
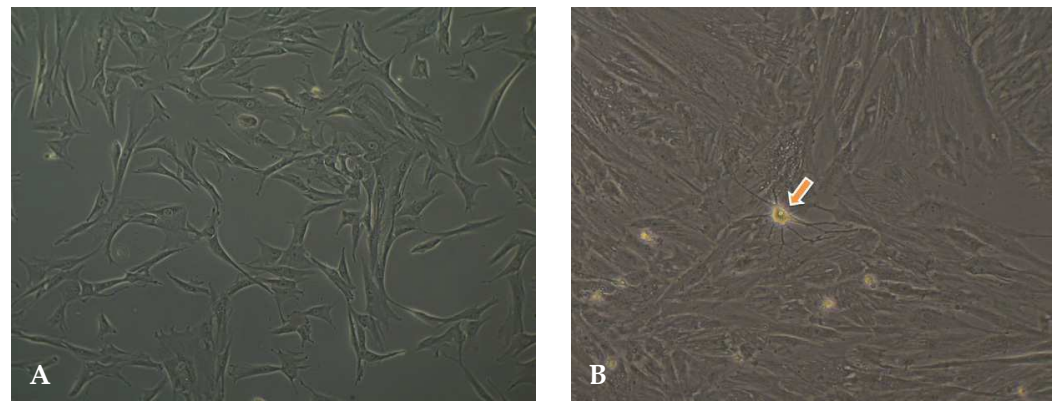

Fig. 3. Undifferentiated mesenchymal stem cells, from Wharton's jelly, exhibiting a star-like shape with a flat morphology (A) and neural-like cells, differentiated after 96 hours with neurogenic medium, formation of typical neural-like multi-branches (B) (100X magnification).

\section{Microsurgical procedures}

Rodents, particularly the rat and the mouse, have become the most frequently utilized animal models for the study of peripheral nerve regeneration because of the widespread availability of these animals as well as the distribution of their nerve trunks which is similar to humans (Mackinnon et al., 1985; Rodriguez \& Navarro, 2004). Although other nerve trunks, especially in the rat forelimb, are getting more and more used for experimental research (Papalia et al., 2006), the rat sciatic nerve is still the far more employed experimental model as it provides a nerve trunk with adequate length and space at the midthigh for surgical manipulation and/or introduction of grafts or guides (Rodriguez \& Navarro, 2004). Although sciatic nerve injuries themselves are rare in humans, this experimental model provides a very realistic testing bench for lesions involving plurifascicular mixed nerves with axons of different size and type competing to reach and reinnervate distal targets (Mackinnon et al., 1985). Common types of experimentally induced injuries include focal crush or freeze injury that causes axonal interruption but preserves the connective sheaths (axonotmesis), complete transection disrupting the whole nerve trunk (neurotmesis) and resection of a nerve segment inducing a gap of certain length. For these reasons our experimental work, concerning the in vivo testing of neurotmesis injury regeneration, was based on the use of Sasco Sprague-Dawley rat sciatic nerve. Usually, the surgeries are performed under an M-650 operating microscope (Leica Microsystems, Wetzlar, Germany). Under deep anaesthesia (ketamine $9 \mathrm{mg} / 100 \mathrm{~g}$; xylazine $1.25 \mathrm{mg} / 100 \mathrm{~g}$, atropine $0.025 \mathrm{mg} / 100$ body weight, intramuscular), the right sciatic nerve is exposed through a skin incision extending from the greater trochanter to the distal mid-half followed by a muscle splitting incision. After nerve mobilisation, a transection injury is performed (neurotmesis) using straight microsurgical scissors, at a level as low as possible, in general, immediately above the terminal nerve ramification. The proximal and distal nerve stumps are inserted $3 \mathrm{~mm}$ into the tube-guide (not covered or covered with cells) and 
held in place, maintaining a nerve gap of $10 \mathrm{~mm}$, with two epineurial sutures using $7 / 0$ monofilament nylon. For neurotmesis without gap, the nerve is reconstructed with an endto-end suture, with two epineural sutures using de 7/0 monofilament nylon. Finally the skin and subcutaneous tissues are closed with a simple-interrupted suture of a non-absorbable filament (Synthofil@, Ethicon). An antibiotic (enrofloxacin, Alsir ${ }^{\circledR} 2.5$ \%, 5 mg / kg b.w., subcutaneously) is always administered to prevent any infections. To prevent autotomy a deterrent substance must be applied to rats' right foot (Kerns et al., 1991; Sporel-Ozakat et al., 1991). All procedures must be performed accordance with the European Communities Council Directive of November 1986 (86/609/EEC).

\section{Functional evaluation}

Our studies of sciatic nerve regeneration after neurotmesis include a post-surgery follow-up period of 20 weeks based on the assumption that, by the end of this time, functional and morphological recovery are complete (Amado et al., 2010; Luis et al., 2007b; Luis et al., 2008; Simoes et al., 2010). Although both morphological and functional data have been used to assess neural regeneration after induced neurotmesis and axonotmesis injuries, the correlation between these two types of assessment is usually poor (Dellon \& Mackinnon, 1989; Shen \& Zhu, 1995). Classical and newly developed methods of assessing nerve recovery, including histomorphometry, retrograde transport of horseradish peroxidase and retrograde fluorescent labelling (Mackinnon et al., 1985; Mackinnon SE, 1988) do not necessarily predict the reestablishment of motor and sensory functions (de Medinaceli et al., 1982; Shen \& Zhu, 1995). Although such techniques are useful in studying the nerve regeneration process, they generally fail in assessing functional recovery (Shen \& Zhu, 1995). In this sense, research on peripheral nerve injury needs to combine both functional and morphological assessment. The use of biomechanical techniques and rat's gait kinematic evaluation is a progress in documenting functional recovery (Varejao et al., $2003 \mathrm{~b})$. Indeed, the use of biomechanical parameters has given valuable insight into the effects of the sciatic denervation/reinnervation, and thus represents an integration of the neural control acting on the ankle and foot muscles (Varejao et al., 2003b; Varejao et al., 2002).

\subsection{Evaluation of motor performance (EPT) and nociceptive function (WRL)}

Motor performance and nociceptive function were evaluated by measuring extensor postural thrust (EPT) and withdrawal reflex latency (WRL), respectively. The animals are tested pre-operatively (week-0), at weeks 1, 2, and every two weeks thereafter until week-20. The EPT was originally proposed by Thalhammer and collaborators, (Thalhammer et al., 1995) as a part of the neurological recovery evaluation in the rat after sciatic nerve injury. For this test, the entire body of the rat, excepting the hind-limbs, is wrapped in a surgical towel. Supporting the animal by the thorax and lowering the affected hind-limb towards the platform of a digital balance, elicits the EPT. As the animal is lowered to the platform, it extends the hind-limb, anticipating the contact made by the distal metatarsus and digits. The force in grams (g) applied to the digital platform balance is recorded. The same procedure is applied to the contra-lateral, unaffected limb. Each EPT test must be repeated 3 times and the average result is considered. The normal (unaffected limb) EPT (NEPT) and experimental EPT (EEPT) values are incorporated into a equation (Equation 1) to derive the percentage of functional deficit (Koka \& Hadlock, 2001). 


\section{Percentage motor deficit $=[(\mathrm{NEPT}-\mathrm{EEPT}) / \mathrm{NEPT}]^{\star} 100$}

The EPT data, originally measured in grams of weight borne by each hindlimb, is expressed as percentage deficit from total bearing weight as determined by the weight borne by the unoperated limb. Potential pitfalls of the EPT do exist. It takes a certain training period for the tester to become comfortable handling the animals, and this comfort level is critical for the animal to behave in a non frightened way. There is also a level of recognition of when the animal is bearing its maximum weight, which is critical since the tester is supporting the body of the animal at all times. Once this recognition takes place, through training by an experienced tester, the examination becomes highly reproducible (Koka \& Hadlock, 2001). To assess the nociceptive withdrawal reflex (WRL), the hotplate test was modified as described by Masters and collaborators (1993). The rat is wrapped in a surgical towel above its waist and then positioned to stand with the affected hind paw on a hot plate at $56^{\circ} \mathrm{C}$ and with the other on a room temperature plate. WRL is defined as the time elapsed from the onset of hotplate contact to withdrawal of the hind paw and measured with a stopwatch. Normal rats withdraw their paws from the hotplate within $4.3 \mathrm{~s}$ or less (Hu et al., 1997). The affected limbs are tested 3 times, with an interval of 2 min between consecutive tests to prevent sensitization, and the three latencies are averaged to obtain a final result (Campbell, 2001). If there is no paw withdrawal after $12 \mathrm{~s}$, the heat stimulus is removed to prevent tissue damage, and the animal is assigned with the maximal WRL of $12 \mathrm{~s}$ (Varejao et al., 2003a).

\subsection{Sciatic functional index (SFI) and static sciatic index (SSI)}

For SFI, animals are tested in a confined walkway measuring $42-\mathrm{cm}$-long and 8.2 -cm-wide, with a dark shelter at the end. A white paper is placed on the floor of the rat walking corridor. The hind paws of the rats are pressed down onto a finger paint-soaked sponge, and they are then allowed to walk down the corridor leaving its hind footprints on the paper. Often, several walks are required to obtain clear print marks of both feet. Prior to any surgical procedure, all rats are trained to walk in the corridor, and a baseline walking track is recorded. Subsequently, walking tracks are recorded pre-operatively (week-0), at weeks 1 , 2 , and every two weeks thereafter until week-20. Several measurements are taken from the footprints: (I) distance from the heel to the third toe, the print length (PL); (II) distance from the first to the fifth toe, the toe spread (TS); and (III) distance from the second to the fourth toe, the intermediary toe spread (ITS). The static footprints are obtained at least during four occasional rest periods. In the static evaluation (SSI) only the parameters TS and ITS, are measured. For both dynamic (SFI) and static assessment (SSI), all measurements are taken from the experimental and normal sides. Four steps should be analyzed per rat. Prints for measurements should be chosen at the time of walking based on clarity and completeness at a point when the rat was walking briskly. The mean distances of three measurements are used to calculate the following factors (dynamic and static):

$$
\begin{gathered}
\text { Toe spread factor }(\mathrm{TSF})=(\mathrm{ETS}-\mathrm{NTS}) / \mathrm{NTS} \\
\text { Intermediate toe spread factor }(\mathrm{ITSF})=(\mathrm{EITS}-\mathrm{NITS}) / \mathrm{NITS} \\
\text { Print length factor }(\mathrm{PLF})=(\mathrm{EPL}-\mathrm{NPL}) / \mathrm{NPL}
\end{gathered}
$$

Where the capital letters $\mathrm{E}$ and $\mathrm{N}$ indicate injured and non-injured side, respectively. The SFI was calculated as described by Bain et al. (1989) (Bain et al., 1989) according to the following equation: 


$$
\begin{gathered}
\mathrm{SFI}=-38.3(\mathrm{EPL}-\mathrm{NPL}) / \mathrm{NPL}+109.5(\mathrm{ETS}-\mathrm{NTS}) / \mathrm{NTS}+13.3(\mathrm{EIT}-\mathrm{NIT}) / \mathrm{NIT}-8.8=(-38.3 \times \\
\mathrm{PLF})+(109.5 \times \mathrm{TSF})+(13.3 \times \mathrm{ITSF})-8.8
\end{gathered}
$$

The SSI is a time-saving and easy technique for accurate functional assessment of peripheral nerve regeneration in rats and is calculated using the static factors, not considering the print length factor (PL), according to the equation (Bervar, 2000; Meek et al., 2004)

$$
\text { SSI }=[(108.44 \times \mathrm{TSF})+(31.85 \times \mathrm{ITSF})]-5.49
$$

For both SFI and SSI, an index score of 0 is considered normal and an index of -100 indicates total impairment. When no footprints are measurable, the index score of -100 is given. In each walking track three footprints must be analyzed by a single observer, and the average of the measurements are used in SFI calculations.

\subsection{Kinematic analysis}

Locomotion is also of higher functional relevance since it involves integrated function of both the motor and sensory systems and their respective components, such as skeletal muscles, sensory endings, efferent and afferent nerve fibers and integrative centers within the central nervous system. Muscles innervated by sciatic nerve branches include both dorsiflexors and plantarflexors and, although in previous studies we focused our kinematic analysis only in the stance phase (Amado et al., 2010; Amado et al., 2008; Luis et al., 2008), we now prefer to include analysis of the ankle joint motion also during the swing phase in order to provide additional information (Joao et al., 2010).

In our previous studies we analyzed ankle kinematics in the sagittal plane during the stance phase of walking either after sciatic nerve transection and repair (Amado et al., 2010; Luis et al., 2008) or after sciatic nerve crush (Amado et al., 2008). The two-dimensional (2D) ankle motion analysis was conducted during voluntary level walking along a corridor with darkened cages at both ends to attract the animals. The lateral walls of the corridor were made of Perspex and a high speed video camera (JVC GR-DVL9800, Nex Jersey, USA) was placed orthogonally to corridor length in order to record ankle motion during walking. Sagittal records of the rat walking were obtained at a frame rate of 100 frames per second and images were semi-automatically digitized using marks at reference points of the rat hindlimb and foot (see Fig. 4B).
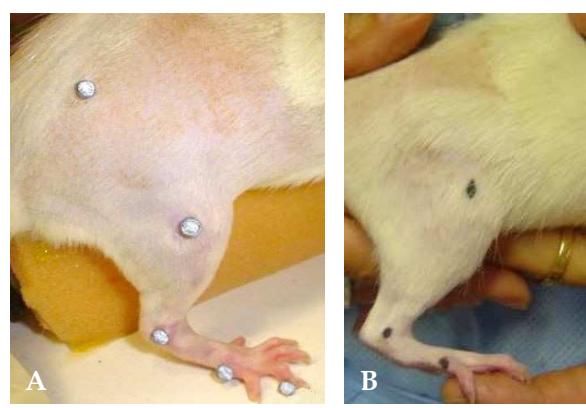

Fig. 4. Reflective markers with $2 \mathrm{~mm}$ diameter were attached to the right hindlimb at bony prominences (from bottom to top): (1) tip of fourth finger, (2) head of fifth metatarsal, (3) lateral malleolus, (4) lateral knee joint, (5) trochanter major (A). Tattoo marks at bony prominences of the right hindlimb: (1) head of fifth metatarsal, (2) lateral malleolus, (3) lateral knee joint (B). 
The trajectories of the segments leg and hindfoot were obtained through this procedure and ankle joint angle was derived by using dot product computation. Ankle kinematics parameters proposed by Varejão et al. (2003) were employed in order to assess functional recovery after sciatic nerve transection and repair and to compare treatments using our tested biomaterials and cellular system. Our ankle joint kinematic analysis generally showed profound walking dysfunction in the weeks after sciatic neurotmesis. Changes affected the whole stance phase and were best characterized by an inability of the animals to perform the normal ankle push off action during the second half of this walking phase (see Fig 5 and Fig.6). Profound ankle kinematic changes during the stance phase of walking were also evident when taking into account angular velocity data. Uninjured animals show a clear ankle angular velocity peak both at the initiation and end of the stance phase. After sciatic transection these two peaks are not observed and the stance phase is characterized by a rather steady increase in positive ankle velocity that corresponds to a progressive augment in ankle dorsiflexion. This abnormal pattern of ankle motion during the stance phase of walking was interpreted as caused by denervation and paralysis of the ankle plantarflexors that were unable to actively extend the ankle against the load of the body weight. In sciatic nerve transected and repaired animals, the recovery of the normal ankle motion pattern of walking is slow and largely incomplete. After 20 weeks of recovery, abnormal ankle motion is still noticed after sciatic nerve neurotmesis (Amado et al., 2010; Luis et al., 2008). In our recent study (Amado et al., 2010), investigating the role of a collagen membrane with and without differentiated N1E-115 cells enwrapped around the transected and end-to-end repaired sciatic nerve, the shape of ankle joint motion during the stance phase showed little improvements until three months after injury (see Fig 5 and Fig.6).
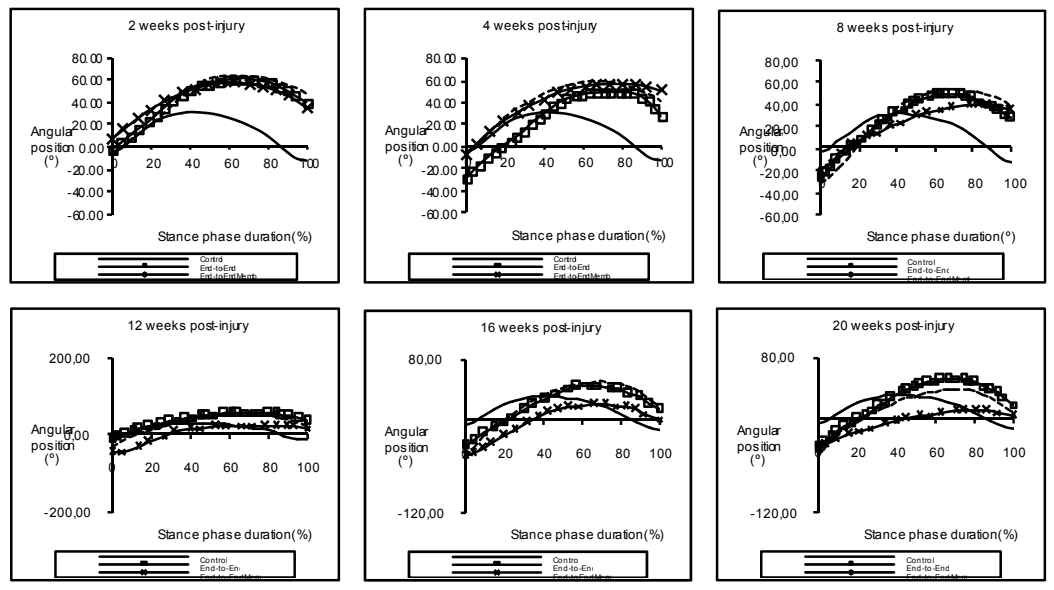

Fig. 5. Kinematics plots in the sagittal plane for the angular position $\left(^{\circ}\right)$ of the ankle as it moves through the stance phase, during the healing period of 20 weeks. The mean of each group is plotted. 

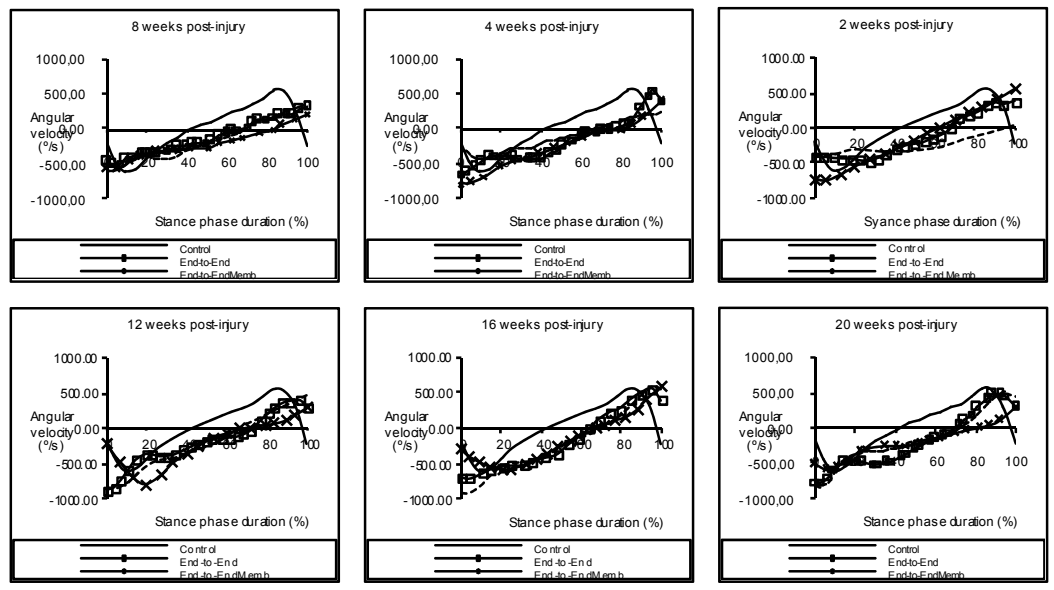

Fig. 6. Kinematics plots in the sagittal plane for the angular velocity $(\% / s)$ of the ankle as it moves through the stance phase, during the healing period of 20 weeks. The mean of each group is plotted.

A progressive improvement in ankle kinematics occurred from this time point up to the end of the 20 weeks recovery time. Such improvement consisted mainly in a slight recovery of ankle plantarflexion at the end of stance phase and lesser peak dorsiflexion at midstance. These changes in ankle kinematics are suggestive of muscle reinnervation and increased force generation ability by the ankle pantarflexor muscle group. In this study, ankle kinematics data were in general agreement with the results of the EPT and WRL tests. The latter tests also demonstrated progressive recovery of motor and sensory function along the follow up time that in the case of the WRL test was accelerated beyond the 12 weeks time point. As for ankle kinematics, the EPT and WRL results also demonstrated incomplete functional recovery in these animals, with slightly better recovery in the end-to-end repair group compared to other two groups. However, ankle kinematics must be envisaged merely as an indirect measure of muscle function. It should be noticed that walking requires fine coordination of limbs motion and definitely quadruped animals have many movement strategies to compensate for deficit in one of the hindlimbs. Through plasticity of integrative structures, animals may develop adaptive patterns that persist even if significant reinnervation takes place. Also, no direct relation exists between more simple tests of muscle strength or of sensory function and a complex action such as walking (Varejao et al., 2003b). Indeed, ankle kinematics data poses a fundamental question. Does recovery of ankle motion during walking signals successful muscle reinnervation and regain of muscle function or else is a product of compensatory changes at whole hindlimb level? To answer this question satisfactorily, walking analysis has to be improved by extending the analysis to hip and knee joints and should be combined with direct measures of muscle activity (Gramsbergen et al., 2000a) and to measures of the force applied to the ground by the walking animal (Howard et al., 2000). To better assess hindlimb joint kinematics during walking, we recently analyzed hip, knee and ankle joint kinematics during recovery of less severe sciatic nerve crush injury, using a more sophisticated motion capture system to track the motion of reflective markers attached to the rat hindlimb (unpublished observations) (see Fig. 4A). 
After this kind of injury, functional recovery is often deemed as complete even on the basis of ankle kinematic analysis with only minor walking changes observed after 12 weeks of recovery. However, after 12 weeks of recovery from complete sciatic nerve crush, changes in hip and knee kinematics during walking were present, when compared to sham-operated control animals. Importantly, such altered hip and knee kinematics were in contrast with total reestablishment of the normal pattern of ankle motion in sciatic-crushed animals.

Individual joint kinematics either in control or nerve-injured animals is characterized by high variability, with notable differences between different animals and even from step to step (Chang et al., 2009). Such high level of variability, which seems to be an intrinsic property of normal quadruped walking, seriously affects the precision of joint kinematic measures of functional recovery after nerve injury. Reducing this variability is a challenge for efficient use of walking analysis to assess functional recovery. Attempts to overcome this limitation include constraining walking velocity by using treadmill walking instead of selfpaced locomotion (Pereira et al., 2006). This, of course, is likely to reduce step-by-step variability in joint kinematics but has the disadvantage of requiring expensive equipment and limits the possibility of combining kinematic analysis with other data, such as ground reaction forces. Other possibilities look at a global, limb-level movement analyses as an alternative to individual joints kinematics (Chang et al., 2009; Sabatier et al., 2011). Also, systematic changes in the biomechanical and movement control constraints of the locomotor task, such as using up- and down-slope walking might also increase the accuracy of walking analysis within the context of peripheral nerve research (Sabatier et al., 2011).

In summary, walking analysis is a promising method to assess functional recovery after hindlimb nerve injury. However, in order to provide accurate measures of functional recovery, walking analysis after hindlimb peripheral nerve injury will have to evolve from simply analyzing ankle kinematics to reach a full biomechanical description of hindlimb motion including analysis of hip, knee and ankle joints. Further refinements of walking analysis in the field of peripheral nerve research using the rat model will probably include the combined use of joint kinematics, ground reaction forces and electromyographical data of muscle activity.

\section{Morphological analysis}

It has been recently pointed out that morphological analysis is the far most common method for the study of peripheral nerve regeneration (Raimondo et al., 2009). Actually, the investigation of nerve morphology can give us important information on various aspects of the regeneration processes which relates with nerve function (Geuna et al., 2009).

Although different types of fixatives can be used for peripheral nerve histology, we fix nerve samples in a solution of $2.5 \%$ purified glutaraldehyde (Histo-line Laboratories s.r.l., Milano, Italy) and $0.5 \%$ saccarose (Merck, Darmstadt, Germany) in 0.1M Sörensen phosphate buffer, $\mathrm{pH} 7.4$, for 6-8h. Nerves are then washed and stored in $0.1 \mathrm{M}$ Sörensen phosphate buffer added with $1.5 \%$ saccarose at $4-6^{\circ} \mathrm{C}$ prior to embedding. Sörensen phosphate buffer is made with $56 \mathrm{~g}$ di-potassium hydrogen phosphate 3-hydrate (K2HPO43H2O) (Fluka, Buchs, Switzerland) and $10.6 \mathrm{~g}$ sodium di-hydrogen phosphate 1-hydrate (NaH2PO4-H2O) (Merck, Darmstadt, Germany) in 1 litre of doubly-distilled water. Just before the embedding, nerves are washed for few minutes in the storage solution and then immersed for $2 \mathrm{~h}$ in $2 \%$ osmium tetroxide (Sigma, St.Louis, MO) in the same buffer solution. The specimens are then carefully dehydrated in passages in ethanol and embedded in 
Glauerts' mixture of resins which is made of equal parts of Araldite $\mathrm{M}$ and the Araldite Härter, HY 964 (Merck, Darmstad, Germany). At the resin mixture, 2\% of accelerator 964, DY 064 is added (Merck, Darmstad, Germany). Finally, the plasticizer $(0.5 \%$ of dibutylphthalate) is added to the resin.
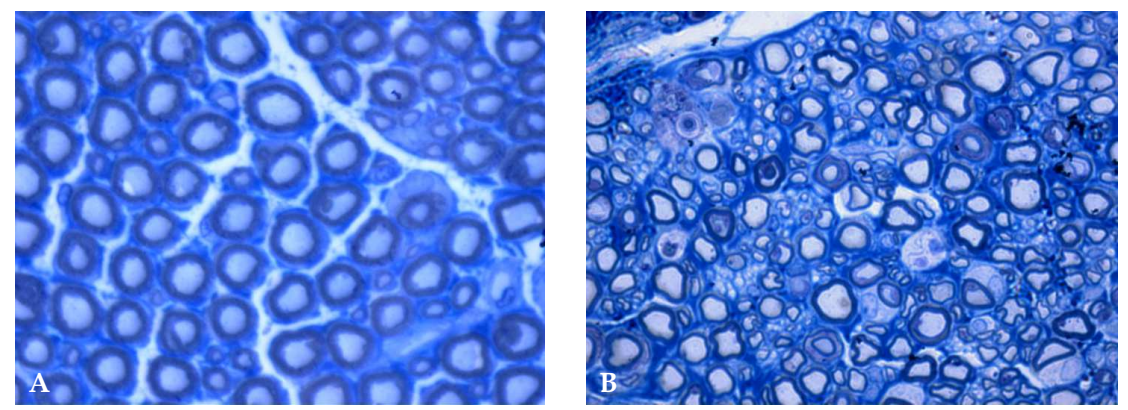

Fig. 7. Representative high resolution photomicrographs of nerve fibers from normal (A) and regenerated (B) rat sciatic nerves after entubulation with collagen nerve guide. Original magnification $=1,000 \mathrm{x}$.

In our laboratory, histomorphometry (stereology) is carried out on toludine-blue-stained semi-thin sections (2.5 micron-thick) of nerve samples using a DM4000B microscope equipped with a DFC320 digital camera and an IM50 image manager system (Leica Microsystems, Wetzlar, Germany). We adopt a final magnification of 6,600x in order to enable accurate identification of myelinated nerve fibers (Figure 9). A 2D-disector method, (Raimondo et al., 2009) is finally used for estimating the total number of myelinated fibers $(N)$, the mean diameter of fiber $(D)$ and axon $(d)$ as well as mean $[(D-d) / 2]$ and g-ratio $(D / d)$ (see Fig.7).

\section{Synopsis of results and discussion}

Peripheral nerve regeneration can be studied in a number of different experimental models based on the use of nerves from both forelimb and hindlimb ( $\mathrm{Hu}$ et al., 1997). The experimental animal model of choice for many researchers remains the rat sciatic nerve. It provides an inexpensive source of mammalian nervous tissue of identical genetic stock that it is easy to work with and well studied (Geuna et al., 2009) and shows a similar capacity for regeneration in rats and sub-humans primates (Johnson et al., 2008). The rat sciatic nerve is a widely used model for the evaluation of motor as well as sensory nerve function at the same time. One of the most addressed issues in experimental nerve repair research is represented by entubulation (Chen et al., 2006). While early studies were more directed towards biological material (Kerns et al., 1991) recent studies have focused more on synthetic materials that are biodegradable. The majority of natural biomaterials used in clinical applications such as hyaluronic acid, collagen, and gelatin are derived from animal sources. In spite of thorough purification methods these materials bear the inherent risk of transfer of viral and prionic diseases and may cause immunological body reactions (Koka \& Hadlock, 2001; Luis et al., 2007b). Synthetic biomaterials are not associated with these risks (Koka \& Hadlock, 2001; Luis et al., 2007b). 
Our group has assessed two types of nerve guides made of a different type of biodegradable synthetic biomaterial, PLGA and caprolactone (Neurolac $\left.{ }^{\circledR}\right)$. Our data showed that both types of nerve guides were a mean to help in the growth of axons and didn't deleteriously interfere with the nerve regeneration process. While the information on the effectiveness of Neurolac ${ }^{\circledR}$ tubes for allowing nerve regeneration was already provided experimentally (; Geuna et al., 2009; Luis et al., 2008) and with patients (Bertleff et al., 2005), the PLGA tubes with the polymers proportion of 90 PLA:10 PLG used in that study have never been tested in vivo before (Luis et al., 2007b). Results of the comparative functional assessment showed that the differences between the two experimental groups were not significant in terms of motor and nociceptive recovery. The EPT proposed by Thalhammer and coworkers (Geuna, 2005) to evaluate the motor function in rats is used routinely by veterinarian neurologists to evaluate the nervous system of small domestic animals. This reflex is initiated by a stretching of the spindles in the interosseous muscles and stimulation of sensory receptors of the foot (Lundborg, 2002). A steady recover of motor deficit occurred throughout the 20week post-surgery period in the group of animals where PLGA and Neurolac ${ }^{\circledR}$ tube-guides were used. As expected, the motor recovery in animals of the end-to-end group occurred significantly faster and to a larger extent when compared to the entubulation groups. Similarly, nociception recovered to a significantly larger extent in the end-to-end group compared to both entubulation groups which, on the contrary, did not differ significantly between them (Luis et al., 2007b). Interestingly, when the nerve is transected and the regenerating axons must bridge a gap, sensory neurons exhibit a faster regenerative pattern than motor neurons (Lundborg, 2002). Morphological analysis showed a different pattern of biodegradation of the two tubes. In fact, while in the nerves repaired by Neurolac ${ }^{\circledR}$ the structure of the polymer was still well preserved at week-20, in the nerves repaired by PLGA guides, the polymer was largely substituted by a connective matrix rich in collagen fibbers and fibroblasts resembling a normal epineurium. These results may suggest that PLGA can be a better biomaterial for fashioning nerve guides since nerves regenerated inside it were more similar to a normal nerve than those regenerated inside Neurolac ${ }^{\circledR}$ guides, although the results of the motor and sensory functional assessment did not disclose significant differences between the two tube-guides and thus both should be considered a good substrate for preparing tubular nerve guides. We have also used the rat sciatic nerve model for investigating the effects of chitosan type III membranes after neurotmesis followed by surgical repair either by direct suture, or autograft or tubulization. Morphological results showed that nerve regeneration occurred when the chitosan type III tube-guide was used and that, at time of withdrawal, Wallerian degeneration was almost completed and substituted by re-growing axons and the accompanying Schwann cells. The results obtained with chitosan type III tube-guides were significantly better, in terms of functional and morphologic recovery, when compared with PLGA90:10 where the regeneration pattern was worse (Simoes et al., 2010). The synergistic effect of a more favorable porous microstructure and physicochemical properties (more wettable and higher water uptake level) of chitosan type III compared to common chitosan, as well as the presence of silica ions, may be responsible for the good results in promoting post-traumatic nerve regeneration (Amado et al., 2008) suggesting that this material may not just work as a simple mechanical scaffold but instead may work as an inducer of nerve regeneration (Amado et al., 2008). The neuroregenerative property of chitosan type III might be explained 
by a direct stimulation of Schwann cell proliferation, axon elongation and myelination (Shirosaki et al., 2005). Yet, the expression of established myelin genes such as PMP22, PO and MBP (Pietak et al., 2007) may be influenced by the presence of silica ions which exert an effect on several glycoprotein expression (Pietak et al., 2007). Taken together, results of this study support the view that hybrid chitosan type III membranes can be a valuable tool for fashioning nerve guides aimed to bridge nerve defects. We also investigated the effects on nerve regeneration of the employment PLGA90:10 nerve guide tubes covered with N1E-115 cells in vitro differentiated in the presence of DMSO for 48 hours (Geuna et al., 2001). Results showed that both motor and sensory functions improved significantly similarly to what occurs in PLGA tubes alone (Luis et al., 2008). Nerve recovery of around $60 \%$ was achieved by week-20, in both groups, reconstructed with PLGA 90:10 tube-guides with or without the cellular system. The pattern of degradation and the degradation products of PLGA90:10 more acidic than the collagen ones do not seem to influence negatively the degree of nerve regeneration during the healing period. On the other hand, the biodegradable non-woven structure of PLGA tubes may offer some advantages in terms of microporosity which may enhance nerve repair. It is not surprising that recovery was significantly better in the group where the gap was reconstructed using the autologous graft since this is still considered the gold standard for peripheral nerve regeneration (Matsuyama et al., 2000). The rationale for the use of the N1E-115 cells was to take advantages of the properties of these cells as a neural-like cellular source of neurotrophic factors (Geuna et al., 2001).

Although tube guides are a suitable choice for peripheral nerve reconstruction, it is known that nerve regeneration and functional recovery are less satisfactory than when nerve repair is done by using an end-to-end neurorraphy or when an autologous nerve graft is applied (Geuna et al., 2009). For example, the risk of neuroma formation in neurotmesis injury is considerable, which is clearly avoided with tube-guide technique. In this sense, enhancing the rate of axonal growth might prevent the occurrence of side effects and might turn nerve regeneration faster, thus improving functional recovery. Neurotrophic factors play an important role in nerve regeneration after injury or disease and it is conceivable that if neurotrophic factors are applied in the close vicinity of the injured nerve their healing potency is optimized. In spite of these premises and contrary to our initial hypothesis, the N1E-115 cells did not facilitate either nerve regeneration or functional recovery and, as far as morphometrical parameters are concerned, results showed that the presence of this cellular system reduced the number and size of the regenerated fibers. These results suggest that this type of nerve guides can partially impair nerve regeneration, at least from a morphological point of view (Luis et al., 2008). The impaired axonal regeneration seems to be the result of N1E-115 cells surrounding and invading the regenerating nerve, since numerous of these cells where seen colonizing the nerve and might have deprived regenerated nerve fibers blood supply (Luis et al., 2008). The use of N1E-115 cells did not promote nerve healing and their use might even derange the nerve regenerating process. Whereas the effects on nerve regeneration were negative, an interesting result of this study was the demonstration that the cell delivery system that we have used was effecting in enabling long-term colonization of the regenerated nerve by transplanted neural cells. Whether the negative effects of using N1E-115 cells as a cellular aid to peripheral neural tissue regeneration extends to other types of cells is not known at present and further studies are warranted to assess the role of other cellular systems, e.g. mesenchymal stem cells, as a foreseeable therapeutic strategy in peripheral nerve regeneration. Our 
experimental results with this cellular system are also important in the perspective of stem cell transplantation employment for improving posttraumatic nerve regeneration with patients (Luis et al., 2008). Undoubtedly, great enthusiasm has raised among researchers and in the general public about cell-based therapies in regenerative medicine (Geuna et al., 2009; Thalhammer et al., 1995). There is a widespread opinion that this type of therapy is also very safe in comparison to other pharmacological or surgical therapeutic approaches. By contrast, recent studies showed that cell-based therapy might be ineffective for improving nerve regeneration (Varejao et al., 2003b) or even have negative effects by hindering the nerve regeneration process after tubulisation repair. Whereas the choice of the cell type to be used for transplantation is certainly very important for the therapeutic success, our present results suggest that the paradigm that donor tissues guide transplanted stem cells to differentiate in the direction that is useful for the regeneration process it is not always true and the possibility that transplanted stem cells choose another differentiation line potentially in contrast with the regenerative process should be always taken in consideration.

\section{Acknowledgements}

This work was supported by the Fundação para a Ciência e Tecnologia (FCT) through the PhD grant SFRH/BD/70211/2010. Financial support was also provided by the European Regional Development Fund, through the QREN Project BIOMAT\&CELL No. 1372.

\section{References}

Amado, S., Rodrigues, J. M., Luis, A. L., Armada-da-Silva, P. A., Vieira, M., Gartner, A., Simoes, M. J., Veloso, A. P., Fornaro, M., Raimondo, S., Varejao, A. S., Geuna, S., \& Mauricio, A. C. (2010). Effects of collagen membranes enriched with in vitrodifferentiated N1E-115 cells on rat sciatic nerve regeneration after end-to-end repair. J Neuroeng Rehabil, 7: 7. ISSN 1743-0003.

Amado, S., Simoes, M. J., Armada da Silva, P. A., Luis, A. L., Shirosaki, Y., Lopes, M. A., Santos, J. D., Fregnan, F., Gambarotta, G., Raimondo, S., Fornaro, M., Veloso, A. P., Varejao, A. S., Mauricio, A. C., \& Geuna, S. (2008). Use of hybrid chitosan membranes and N1E-115 cells for promoting nerve regeneration in an axonotmesis rat model. Biomaterials, 29(33): 4409-4419. ISSN 0142-9612.

Amano, T., Richelson, E., \& Nirenberg, M. (1972). Neurotransmitter synthesis by neuroblastoma clones (neuroblast differentiation-cell culture-choline acetyltransferase-acetylcholinesterase-tyrosine hydroxylase-axons-dendrites). Proc Natl Acad Sci U S A, 69(1): 258-263. ISSN 0027-8424.

Archibald, S. J., Shefner, J., Krarup, C., \& Madison, R. D. (1995). Monkey median nerve repaired by nerve graft or collagen nerve guide tube. J Neurosci, 15(5 Pt 2): 41094123. ISSN 0270-6474.

Bain, J. R., Mackinnon, S. E., \& Hunter, D. A. (1989). Functional evaluation of complete sciatic, peroneal, and posterior tibial nerve lesions in the rat. Plast Reconstr Surg, 83(1): 129-138. ISSN 0032-1052.

Baksh, D., Yao, R., \& Tuan, R. S. (2007). Comparison of proliferative and multilineage differentiation potential of human mesenchymal stem cells derived from umbilical cord and bone marrow. Stem Cells, 25(6): 1384-1392. ISSN 1384-1392. 
Beer, G. M., Steurer, J., \& Meyer, V. E. (2001). Standardizing nerve crushes with a nonserrated clamp. J Reconstr Microsurg, 17(7): 531-534. ISSN 0743-684X.

Bertleff, M. J., Meek, M. F., \& Nicolai, J. P. (2005). A prospective clinical evaluation of biodegradable neurolac nerve guides for sensory nerve repair in the hand. J Hand Surg Am, 30(3): 513-518. ISSN 0363-5023.

Bervar, M. (2000). Video analysis of standing--an alternative footprint analysis to assess functional loss following injury to the rat sciatic nerve. J Neurosci Methods, 102(2): 109-116. ISSN 0165-0270.

Bichara, D. A., Zhao, X., Hwang, N. S., Bodugoz-Senturk, H., Yaremchuk, M. J., Randolph, M. A., \& Muratoglu, O. K. (2010). Porous poly(vinyl alcohol)-alginate gel hybrid construct for neocartilage formation using human nasoseptal cells. J Surg Res, 163(2): 331-336. ISSN 1095-8673.

Bini, T. B., Gao, S., Xu, X., Wang, S., Ramakrishna, S., \& Leong, K. W. (2004). Peripheral nerve regeneration by microbraided poly(L-lactide-co-glycolide) biodegradable polymer fibers. J Biomed Mater Res A, 68(2): 286-295. ISSN 1549-3296.

Campbell, J. N. (2001). Nerve lesions and the generation of pain. Muscle Nerve, 24(10): 12611273. ISSN 0148-639X.

Can, A., \& Karahuseyinoglu, S. (2007). Concise review: human umbilical cord stroma with regard to the source of fetus-derived stem cells. Stem Cells, 25(11): 2886-2895. ISSN $1549-4918$.

Ceballos, D., Navarro, X., Dubey, N., Wendelschafer-Crabb, G., Kennedy, W. R., \& Tranquillo, R. T. (1999). Magnetically aligned collagen gel filling a collagen nerve guide improves peripheral nerve regeneration. Exp Neurol, 158(2): 290-300. ISSN 0014-4887.

Chamberlain, L. J., Yannas, I. V., Hsu, H. P., \& Spector, M. (2000). Connective tissue response to tubular implants for peripheral nerve regeneration: the role of myofibroblasts. J Comp Neurol, 417(4): 415-430. ISSN 0021-9967.

Chang, Y. H., Auyang, A. G., Scholz, J. P., \& Nichols, T. R. (2009). Whole limb kinematics are preferentially conserved over individual joint kinematics after peripheral nerve injury. J Exp Biol, 212(Pt 21): 3511-3521. ISSN 3511-3521.

Chen, X., Wang, X. D., Chen, G., Lin, W. W., Yao, J., \& Gu, X. S. (2006). Study of in vivo differentiation of rat bone marrow stromal cells into schwann cell-like cells. Microsurgery, 26(2): 111-115. ISSN 0738-1085.

Chen, Z. L., Yu, W. M., \& Strickland, S. (2007). Peripheral regeneration. Annu Rev Neurosci, 30: 209-233. ISSN 0147-006X.

Conconi, M. T., Burra, P., Di Liddo, R., Calore, C., Turetta, M., Bellini, S., Bo, P., Nussdorfer, G. G., \& Parnigotto, P. P. (2006). CD105(+) cells from Wharton's jelly show in vitro and in vivo myogenic differentiative potential. Int J Mol Med, 18(6): 1089-1096. ISSN 1107-3756.

Cui, L., Jiang, J., Wei, L., Zhou, X., Fraser, J. L., Snider, B. J., \& Yu, S. P. (2008). Transplantation of embryonic stem cells improves nerve repair and functional recovery after severe sciatic nerve axotomy in rats. Stem Cells, 26(5): 1356-1365. ISSN 1549-4918.

de Medinaceli, L., Freed, W. J., \& Wyatt, R. J. (1982). An index of the functional condition of rat sciatic nerve based on measurements made from walking tracks. Exp Neurol, 77(3): 634-643. ISSN 0014-4886. 
Dellon, A. L., \& Mackinnon, S. E. (1989). Sciatic nerve regeneration in the rat. Validity of walking track assessment in the presence of chronic contractures. Microsurgery, 10(3): 220-225. ISSN 0738-1085.

Den Dunnen, W. F., Meek, M. F., Robinson, P. H., \& Schakernraad, J. M. (1998). Peripheral nerve regeneration through $\mathrm{P}(\mathrm{DLLA}-\mathrm{epsilon}-\mathrm{CL})$ nerve guides. J Mater Sci Mater Med, 9(12): 811-814. ISSN 0957-4530.

Fields, R. D., Le Beau, J. M., Longo, F. M., \& Ellisman, M. H. (1989). Nerve regeneration through artificial tubular implants. Prog Neurobiol, 33(2): 87-134. ISSN 0301-0082.

Fu, Y. S., Shih, Y. T., Cheng, Y. C., \& Min, M. Y. (2004). Transformation of human umbilical mesenchymal cells into neurons in vitro. J Biomed Sci, 11(5): 652-660. ISSN 10217770 .

Geuna, S. (2005). The revolution of counting "tops": two decades of the disector principle in morphological research. Microsc Res Tech, 66(5): 270-274. ISSN 1059-910X.

Geuna, S., Raimondo, S., Ronchi, G., Di Scipio, F., Tos, P., Czaja, K., \& Fornaro, M. (2009). Chapter 3: Histology of the peripheral nerve and changes occurring during nerve regeneration. Int Rev Neurobiol, 87: 27-46. ISSN 0074-7742.

Geuna, S., Tos, P., Guglielmone, R., Battiston, B., \& Giacobini-Robecchi, M. G. (2001). Methodological issues in size estimation of myelinated nerve fibers in peripheral nerves. Anat Embryol (Berl), 204(1): 1-10. ISSN 0340-2061.

Gramsbergen, A., Ijkema-Paassen, J., \& Meek, M. F. (2000). Sciatic Nerve Transection in the Adult Rat: Abnormal EMG Patterns during Locomotion by Aberrant Innervation of Hindleg Muscles. Experimental Neurology, 161(1): 183-193. ISSN 0014-4886.

Grant, C., Twigg, P., Egan, A., Moody, A., Smith, A., Eagland, D., Crowther, N., \& Britland, S. (2006). Poly(vinyl alcohol) hydrogel as a biocompatible viscoelastic mimetic for articular cartilage. Biotechnol Prog, 22(5): 1400-1406. ISSN 8756-7938.

Grimpe, B., \& Silver, J. (2002). The extracellular matrix in axon regeneration. Prog Brain Res, 137: 333-349. ISSN 0079-6123.

Gu, X., Ding, F., Yang, Y., \& Liu, J. (2011). Construction of tissue engineered nerve grafts and their application in peripheral nerve regeneration. Prog Neurobiol, 93(2): 204-230. ISSN 1873-5118.

Hood, B., Levene, H. B., \& Levi, A. D. (2009). Transplantation of autologous Schwann cells for the repair of segmental peripheral nerve defects. Neurosurg Focus, 26(2): E4. ISSN 1092-0684.

Howard, C. S., Blakeney, D. C., Medige, J., Moy, O. J., \& Peimer, C. A. (2000). Functional assessment in the rat by ground reaction forces. J Biomech, 33(6): 751-757. ISSN 0021-9290.

$\mathrm{Hu}, \mathrm{D} ., \mathrm{Hu}, \mathrm{R} .$, \& Berde, C. (1997). Neurologic evaluation of infant and adult rats before and after sciatic nerve blockade. Anesthesiology, 86: 957-965. ISSN 003-3022.

Huang, Y. C., \& Huang, Y. Y. (2006). Biomaterials and strategies for nerve regeneration. Artif Organs, 30(7): 514-522. ISSN 0160-564X.

Itoh, S., Suzuki, M., Yamaguchi, I., Takakuda, K., Kobayashi, H., Shinomiya, K., \& Tanaka, J. (2003). Development of a nerve scaffold using a tendon chitosan tube. Artif Organs, 27(12): 1079-1088. ISSN 0160-564X.

Joao, F., Amado, S., Veloso, A., Armada-da-Silva, P., \& Mauricio, A. C. (2010). Anatomical reference frame versus planar analysis: implications for the kinematics of the rat hindlimb during locomotion. Rev Neurosci, 21(6): 469-485. ISSN 0334-1763. 
Johnson, E. O., \& Soucacos, P. N. (2008). Nerve repair: experimental and clinical evaluation of biodegradable artificial nerve guides. Injury, 39 Suppl 3: S30-36. ISSN 1879-0267.

Johnson, W. L., Jindrich, D. L., Roy, R. R., \& Reggie Edgerton, V. (2008). A three-dimensional model of the rat hindlimb: musculoskeletal geometry and muscle moment arms. $J$ Biomech, 41(3): 610-619. ISSN 0021-9290.

Kadivar, M., Khatami, S., Mortazavi, Y., Shokrgozar, M. A., Taghikhani, M., \& Soleimani, M. (2006). In vitro cardiomyogenic potential of human umbilical vein-derived mesenchymal stem cells. Biochem Biophys Res Commun, 340(2): 639-647. ISSN 0006291X.

Karahuseyinoglu, S., Kocaefe, C., Balci, D., Erdemli, E., \& Can, A. (2008). Functional structure of adipocytes differentiated from human umbilical cord stroma-derived stem cells. Stem Cells, 26(3): 682-691. ISSN 1549-4418.

Kerns, J. M., Braverman, B., Mathew, A., Lucchinetti, C., \& Ivankovich, A. D. (1991). A comparison of cryoprobe and crush lesions in the rat sciatic nerve. Pain, 47(1): 3139. ISSN 0304-3959.

Koka, R., \& Hadlock, T. A. (2001). Quantification of functional recovery following rat sciatic nerve transection. Exp Neurol, 168(1): 192-195. ISSN 0014-4886.

Kranenburg, O., Scharnhorst, V., Van der Eb, A. J., \& Zantema, A. (1995). Inhibition of cyclin-dependent kinase activity triggers neuronal differentiation of mouse neuroblastoma cells. J Cell Biol, 131(1): 227-234. ISSN 0021-9525.

Luis, A. L., Amado, S., Geuna, S., Rodrigues, J. M., Simoes, M. J., Santos, J. D., Fregnan, F., Raimondo, S., Veloso, A. P., Ferreira, A. J., Armada-da-Silva, P. A., Varejao, A. S., \& Mauricio, A. C. (2007a). Long-term functional and morphological assessment of a standardized rat sciatic nerve crush injury with a non-serrated clamp. J Neurosci Methods, 163(1): 92-104. ISSN 0165-0270.

Luis, A. L., Rodrigues, J. M., Amado, S., Veloso, A. P., Armada-Da-Silva, P. A., Raimondo, S., Fregnan, F., Ferreira, A. J., Lopes, M. A., Santos, J. D., Geuna, S., Varejao, A. S., \& Mauricio, A. C. (2007b). PLGA 90/10 and caprolactone biodegradable nerve guides for the reconstruction of the rat sciatic nerve. Microsurgery, 27(2): 125-137. ISSN 0738-1085.

Luis, A. L., Rodrigues, J. M., Geuna, S., Amado, S., Simoes, M. J., Fregnan, F., Ferreira, A. J., Veloso, A. P., Armada-da-Silva, P. A., Varejao, A. S., \& Mauricio, A. C. (2008). Neural cell transplantation effects on sciatic nerve regeneration after a standardized crush injury in the rat. Microsurgery, 28(6): 458-470. ISSN 1098-2752.

Lundborg, G. (2002). Enhancing posttraumatic nerve regeneration. J Peripher Nerv Syst, 7(3): 139-140. ISSN 1085-9489.

Lundborg, G., Dahlin, L., Danielsen, N., \& Zhao, Q. (1994). Trophism, tropism, and specificity in nerve regeneration. J Reconstr Microsurg, 10(5): 345-354. ISSN 0743$684 X$.

Mackinnon, S. E., Hudson, A. R., \& Hunter, D. A. (1985). Histologic assessment of nerve regeneration in the rat. Plast Reconstr Surg, 75(3): 384-388. ISSN 0032-1052.

Marcus, A. J., \& Woodbury, D. (2008). Fetal stem cells from extra-embryonic tissues: do not discard. J Cell Mol Med, 12(3): 730-742. ISSN 1582-1838.

Marreco, P. R., da Luz Moreira, P., Genari, S. C., \& Moraes, A. M. (2004). Effects of different sterilization methods on the morphology, mechanical properties, and cytotoxicity 
of chitosan membranes used as wound dressings. J Biomed Mater Res B Appl Biomater, 71(2): 268-277. ISSN 1552-4973.

Masters, D., Berde, C., Dutta, S., Griggs, C., Hu, D., Kupsky, W., \& Langer, R. (1993). Prolonged regional nerve blockade by controlled release of local anesthetic from a biodegradable polymer matrix. Anesthesiology, 79: 340-346.

Matsuyama, T., Mackay, M., \& Midha, R. (2000). Peripheral nerve repair and grafting techniques: a review. Neurol Med Chir (Tokyo), 40(4): 187-199. ISSN 0470-8105.

May, M. (1983). Trauma to the facial nerve. Otolaryngol Clin North Am, 16(3): 661-670. ISSN 0030-6665.

Meek, M. F., \& Coert, J. H. (2002). Clinical use of nerve conduits in peripheral-nerve repair: review of the literature. J Reconstr Microsurg, 18(2): 97-109. ISSN 0743-684X.

Meek, M. F., Jansen, K., Steendam, R., van Oeveren, W., van Wachem, P. B., \& van Luyn, M. J. (2004). In vitro degradation and biocompatibility of poly(DL-lactide-epsiloncaprolactone) nerve guides. J Biomed Mater Res A, 68(1): 43-51. ISSN 1549-3296.

Mligiliche, N. L., Tabata, Y., Kitada, M., Endoh, K., Okamato, K., Fujimoto, E., \& Ide, C. (2003). Poly lactic acid--caprolactone copolymer tube with a denatured skeletal muscle segment inside as a guide for peripheral nerve regeneration: a morphological and electrophysiological evaluation of the regenerated nerves. Anat Sci Int, 78(3): 156-161. ISSN 1447-6959.

Papalia, I., Tos, P., Scevola, A., Raimondo, S., \& Geuna, S. (2006). The ulnar test: a method for the quantitative functional assessment of posttraumatic ulnar nerve recovery in the rat. J Neurosci Methods, 154(1-2): 198-203. ISSN 0165-0270.

Pereira, J. E., Cabrita, A. M., Filipe, V. M., Bulas-Cruz, J., Couto, P. A., Melo-Pinto, P., Costa, L. M., Geuna, S., Mauricio, A. C., \& Varejao, A. S. (2006). A comparison analysis of hindlimb kinematics during overground and treadmill locomotion in rats. Behav Brain Res, 172(2): 212-218. ISSN 0166-4328.

Pietak, A. M., Reid, J. W., Stott, M. J., \& Sayer, M. (2007). Silicon substitution in the calcium phosphate bioceramics. Biomaterials, 28(28): 4023-4032. ISSN 0142-9612.

Raimondo, S., Fornaro, M., Di Scipio, F., Ronchi, G., Giacobini-Robecchi, M. G., \& Geuna, S. (2009). Chapter 5: Methods and protocols in peripheral nerve regeneration experimental research: part II-morphological techniques. Int Rev Neurobiol, 87: 81103. ISSN 0074-7742.

Rodrigues, J. M., Luis, A. L., Lobato, J. V., Pinto, M. V., Faustino, A., Hussain, N. S., Lopes, M. A., Veloso, A. P., Freitas, M., Geuna, S., Santos, J. D., \& Mauricio, A. C. (2005). Intracellular $\mathrm{Ca} 2+$ concentration in the N1E-115 neuronal cell line and its use for peripheric nerve regeneration. Acta Med Port, 18(5): 323-328. ISSN 1646-0758.

Rodriguez JF, V.-C. A., Navarro X. (2004). Regeneration and funcional recovery following peripheral nerve injury. Drugs Discovery Today: Disease Models, 1(2): 177-185.

Sabatier, M. J., To, B. N., Nicolini, J., \& English, A. W. (2011). Effect of slope and sciatic nerve injury on ankle muscle recruitment and hindlimb kinematics during walking in the rat. J Exp Biol, 214(Pt 6): 1007-1016. ISSN 1007-1016.

Schmidt, C. E., \& Leach, J. B. (2003). Neural tissue engineering: strategies for repair and regeneration. Annu Rev Biomed Eng, 5: 293-347. ISSN 1523-9829.

Senel, S., \& McClure, S. J. (2004). Potential applications of chitosan in veterinary medicine. Advanced Drug Delivery Reviews, 56(10): 1467-1480. 
Shen, N., \& Zhu, J. (1995). Application of sciatic functional index in nerve functional assessment. Microsurgery, 16(8): 552-555. ISSN 0738-1085.

Shirosaki, Y., Tsuru, K., Hayakawa, S., Osaka, A., Lopes, M. A., Santos, J. D., \& Fernandes, M. H. (2005). In vitro cytocompatibility of MG63 cells on chitosan-organosiloxane hybrid membranes. Biomaterials, 26(5): 485-493.

Simoes, M. J., Amado, S., Gartner, A., Armada-Da-Silva, P. A., Raimondo, S., Vieira, M., Luis, A. L., Shirosaki, Y., Veloso, A. P., Santos, J. D., Varejao, A. S., Geuna, S., \& Mauricio, A. C. (2010). Use of chitosan scaffolds for repairing rat sciatic nerve defects. Ital J Anat Embryol, 115(3): 190-210. ISSN 1122-6714.

Smith, K. J., \& Hall, S. M. (1988). Peripheral demyelination and remyelination initiated by the calcium-selective ionophore ionomycin: in vivo observations. J Neurol Sci, 83(1): 37-53. ISSN 0022-510X.

Sporel-Ozakat, R. E., Edwards, P. M., Hepgul, K. T., Savas, A., \& Gispen, W. H. (1991). A simple method for reducing autotomy in rats after peripheral nerve lesions. Journal of Neuroscience Methods, 36(2-3): 263-265.

Tateishi, T., Chen, G., \& Ushida, T. (2002). Biodegradable porous scaffolds for tissue engineering. J Artif Organs, 5: 77-83.

Thalhammer, J. G., Vladimirova, M., Bershadsky, B., \& Strichartz, G. R. (1995). Neurologic evaluation of the rat during sciatic nerve block with lidocaine. Anesthesiology, 82(4): 1013-1025. ISSN 0003-3022.

Trump, B. F., \& Berezesky, I. K. (1995). Calcium-mediated cell injury and cell death. FASEB J, 9(2): 219-228. ISSN 0892-6638.

Tsien, R. Y. (1989). Fluorescent probes of cell signaling. Annu Rev Neurosci, 12: 227-253. ISSN 0147-006X.

Varejao, A. S., Cabrita, A. M., Geuna, S., Patricio, J. A., Azevedo, H. R., Ferreira, A. J., \& Meek, M. F. (2003a). Functional assessment of sciatic nerve recovery: biodegradable poly (DLLA-epsilon-CL) nerve guide filled with fresh skeletal muscle. Microsurgery, 23(4): 346-353. ISSN 0738-1085.

Varejao, A. S., Cabrita, A. M., Meek, M. F., Bulas-Cruz, J., Filipe, V. M., Gabriel, R. C., Ferreira, A. J., Geuna, S., \& Winter, D. A. (2003b). Ankle kinematics to evaluate functional recovery in crushed rat sciatic nerve. Muscle Nerve, 27(6): 706-714. ISSN 0148-639X.

Varejao, A. S., Cabrita, A. M., Meek, M. F., Bulas-Cruz, J., Gabriel, R. C., Filipe, V. M., MeloPinto, P., \& Winter, D. A. (2002). Motion of the foot and ankle during the stance phase in rats. Muscle Nerve, 26(5): 630-635. ISSN 1652-1670.

Waitayawinyu, T., Parisi, D. M., Miller, B., Luria, S., Morton, H. J., Chin, S. H., \& Trumble, T. E. (2007). A comparison of polyglycolic acid versus type 1 collagen bioabsorbable nerve conduits in a rat model: an alternative to autografting. J Hand Surg Am, 32(10): 1521-1529. ISSN 0363-5023.

Wang, H. B., Mullins, M. E., Cregg, J. M., Hurtado, A., Oudega, M., Trombley, M. T., \& Gilbert, R. J. (2009). Creation of highly aligned electrospun poly-L-lactic acid fibers for nerve regeneration applications. J Neural Eng, 6(1): 016001. ISSN 1751-2560.

Wang, H. S., Hung, S. C., Peng, S. T., Huang, C. C., Wei, H. M., Guo, Y. J., Fu, Y. S., Lai, M. C., \& Chen, C. C. (2004). Mesenchymal stem cells in the Wharton's jelly of the human umbilical cord. Stem Cells, 22(7): 1330-1337. ISSN 1330-1337. 
Wang, W., Itoh, S., Matsuda, A., Ichinose, S., Shinomiya, K., Hata, Y., \& Tanaka, J. (2008). Influences of mechanical properties and permeability on chitosan nano/microfiber mesh tubes as a scaffold for nerve regeneration. J Biomed Mater Res A, 84(2): 557-566. 1549-3296.

Weiss, M. L., Medicetty, S., Bledsoe, A. R., Rachakatla, R. S., Choi, M., Merchav, S., Luo, Y., Rao, M. S., Velagaleti, G., \& Troyer, D. (2006). Human umbilical cord matrix stem cells: preliminary characterization and effect of transplantation in a rodent model of Parkinson's disease. Stem Cells, 24(3): 781-792. ISSN 1066-5099.

Wu, L. F., Wang, N. N., Liu, Y. S., \& Wei, X. (2009). Differentiation of Wharton's jelly primitive stromal cells into insulin-producing cells in comparison with bone marrow mesenchymal stem cells. Tissue Eng Part A, 15(10): 2865-2873. ISSN 1937$335 X$.

Yang, C. C., Shih, Y. H., Ko, M. H., Hsu, S. Y., Cheng, H., \& Fu, Y. S. (2008). Transplantation of human umbilical mesenchymal stem cells from Wharton's jelly after complete transection of the rat spinal cord. PLoS One, 3(10): e3336. ISSN 1932-66203.

Yoshii, S., \& Oka, M. (2001). Peripheral nerve regeneration along collagen filaments. Brain Res, 888(1): 158-162. ISSN 0006-8993. 


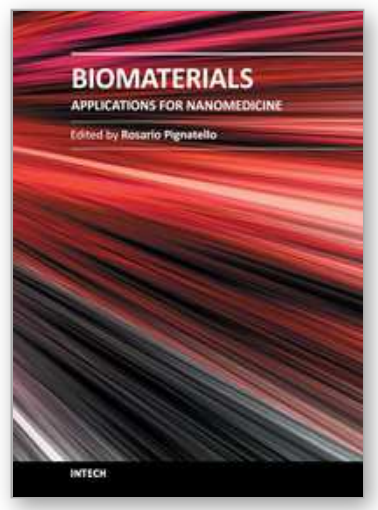

\author{
Biomaterials Applications for Nanomedicine \\ Edited by Prof. Rosario Pignatello
}

ISBN 978-953-307-661-4

Hard cover, 458 pages

Publisher InTech

Published online 16, November, 2011

Published in print edition November, 2011

These contribution books collect reviews and original articles from eminent experts working in the interdisciplinary arena of biomaterial development and use. From their direct and recent experience, the readers can achieve a wide vision on the new and ongoing potentialities of different synthetic and engineered biomaterials. Contributions were selected not based on a direct market or clinical interest, but on results coming from a very fundamental studies. This too will allow to gain a more general view of what and how the various biomaterials can do and work for, along with the methodologies necessary to design, develop and characterize them, without the restrictions necessary imposed by industrial or profit concerns. Biomaterial constructs and supramolecular assemblies have been studied, for example, as drug and protein carriers, tissue scaffolds, or to manage the interactions between artificial devices and the body. In this volume of the biomaterial series have been gathered in particular reviews and papers focusing on the application of new and known macromolecular compounds to nanotechnology and nanomedicine, along with their chemical and mechanical engineering aimed to fit specific biomedical purposes.

\title{
How to reference
}

In order to correctly reference this scholarly work, feel free to copy and paste the following:

Ana Colette Maurício, Andrea Gärtner, Paulo Armada-da-Silva, Sandra Amado, Tiago Pereira, António Prieto Veloso, Artur Varejão, Ana Lúcia Luîs and Stefano Geuna (2011). Cellular Systems and Biomaterials for Nerve Regeneration in Neurotmesis Injuries, Biomaterials Applications for Nanomedicine, Prof. Rosario Pignatello (Ed.), ISBN: 978-953-307-661-4, InTech, Available from: http://www.intechopen.com/books/biomaterialsapplications-for-nanomedicine/cellular-systems-and-biomaterials-for-nerve-regeneration-in-neurotmesisinjuries

\section{INTECH}

open science | open minds

\author{
InTech Europe \\ University Campus STeP Ri \\ Slavka Krautzeka 83/A \\ 51000 Rijeka, Croatia \\ Phone: +385 (51) 770447 \\ Fax: +385 (51) 686166 \\ www.intechopen.com
}

\author{
InTech China \\ Unit 405, Office Block, Hotel Equatorial Shanghai \\ No.65, Yan An Road (West), Shanghai, 200040, China \\ 中国上海市延安西路65号上海国际贵都大饭店办公楼405单元 \\ Phone: +86-21-62489820 \\ Fax: +86-21-62489821
}


(C) 2011 The Author(s). Licensee IntechOpen. This is an open access article distributed under the terms of the Creative Commons Attribution 3.0 License, which permits unrestricted use, distribution, and reproduction in any medium, provided the original work is properly cited. 